Table 1 Summary of the main clinical and genetic features of the 8 Chinese adult patients

\begin{tabular}{|c|c|c|c|c|c|c|c|c|}
\hline \multicolumn{9}{|c|}{ with TRAPS } \\
\hline Patient & 1 & 2 & 3 & 4 & 5 & 6 & 7 & 8 \\
\hline Sexuality & M & $\mathrm{F}$ & $M$ & $\mathrm{~F}$ & M & $M$ & M & M \\
\hline Nationality & Han & Han & Han & Han & Han & Han & Manchu & Han \\
\hline $\begin{array}{l}\text { Age at onset } \\
\text { (years) }\end{array}$ & 0.5 & 17 & 5 & 5 & 2.5 & 2 & 38.5 & 3 \\
\hline $\begin{array}{l}\text { Age at } \\
\text { diagnosis } \\
\text { (years) }\end{array}$ & 17 & 24 & 24 & 25 & 16 & 52 & 40 & 27 \\
\hline $\begin{array}{l}\text { Diagnosis } \\
\text { delay (years) }\end{array}$ & 16.5 & 7 & 19 & 20 & 13.5 & 50 & 1.5 & 24 \\
\hline Family History & - & - & - & + & - & - & - & - \\
\hline TNFRSF1A & m.1735A & G65 & S29 & C58 & F89L & V202 & c.769-23(IVS8 & C99 \\
\hline Variant & $>G$ & E & 이 & $\mathrm{R}$ & & G & $\mid T>C$ & G \\
\hline $\begin{array}{l}\text { Variant in } \\
\text { other genes }\end{array}$ & - & - & - & - & $\begin{array}{c}\text { R202Q in } \\
\text { MEFV }\end{array}$ & - & $\begin{array}{c}\text { D424E in } \\
\text { MEFV, G39V } \\
\text { in NLRP12 }\end{array}$ & - \\
\hline Fever & + & + & + & + & + & + & + & + \\
\hline Duration & $>3 w$ & $1 w$ & $\begin{array}{c}2-3 \\
d\end{array}$ & $\begin{array}{c}1-2 \\
w\end{array}$ & $1-2 w$ & $2-3 d$ & $2-3 w$ & $1 w$ \\
\hline Interval & $<1 w$ & $3 m$ & $\begin{array}{c}1-2 \\
m\end{array}$ & $\begin{array}{l}\geq 1 \\
m\end{array}$ & $\geq 1 \mathrm{~m}$ & $\begin{array}{l}< \\
1 \mathrm{~m}\end{array}$ & $>1 w$ & $1 \mathrm{~m}$ \\
\hline Rash & + & - & - & + & + & + & + & + \\
\hline $\begin{array}{l}\text { Periorbital } \\
\text { edema }\end{array}$ & - & - & - & - & - & - & - & + \\
\hline Conjunctivitis & - & - & + & - & - & + & + & - \\
\hline $\begin{array}{l}\text { Arthralgia/Art } \\
\text { hritis }\end{array}$ & + & - & + & - & - & + & - & + \\
\hline Myalgia & + & - & - & + & + & + & + & - \\
\hline $\begin{array}{l}\text { Abdominal } \\
\text { pain }\end{array}$ & - & + & - & + & - & + & - & + \\
\hline Angina & - & + & - & + & - & + & + & + \\
\hline Headache & + & - & - & - & - & + & + & + \\
\hline
\end{tabular}

Table 2 Comparison of phenotypic and genotypic features among reported cohorts

\begin{tabular}{|c|c|c|c|}
\hline Cohorts & PUMCH $(n=8)$ & Japan $(n=51)$ & Europe $(n=158)$ \\
\hline$M: F$ & $6: 2$ & $22: 29$ & $78: 80$ \\
\hline $\begin{array}{l}\text { Young onset ( }<18 \\
\text { years old, \%) }\end{array}$ & 87.5 & $68.1^{\circ}$ & 78 \\
\hline Age at onset (years) & $4(0.5-38.5)$ & $N D^{*}$ & $4.3(0-63)$ \\
\hline Age at diagnosis (years) & $24.5(14-52)$ & ND & $25.9(0-77)$ \\
\hline Diagnosis delay (years) & $17.8(1.5-50.5)$ & ND & $10.3(0-77)$ \\
\hline Family history (\%) & 12.5 & 45.1 & ND \\
\hline Fever $\left(>38^{\circ} \mathrm{C}, \%\right)$ & 100 & 100 & 84 \\
\hline Rash (\%) & 75 & 55 & 63 \\
\hline Periorbital edema (\%) & 12.5 & 9.1 & 20 \\
\hline Conjunctivitis (\%) & 37.5 & 18.2 & 22 \\
\hline Arthralgia/Arthritis (\%) & 50 & 59 & 64 \\
\hline Myalgia (\%) & 54 & 43 & 70 \\
\hline Abdominal Pain (\%) & 50 & 36 & 70 \\
\hline Pharyngitis (\%) & 62.5 & ND & 21 \\
\hline Headache (\%) & 50 & 23 & 23 \\
\hline Diarrhea (\%) & 12.5 & ND & 18 \\
\hline Chest pain (\%) & 0 & 13.6 & 25 \\
\hline Amyloidosis (\%) & 0 & 0 & 10 \\
\hline
\end{tabular}

"Age onset $<20$ years old; "ND: No Data

REFERENCES:

[1] Lachmann $\mathrm{HJ}$, et al. The phenotype of TNF receptor-associated autoinflammatory syndrome (TRAPS) at presentation: a series of 158 cases from the Eurofever/EUROTRAPS international registry. Ann Rheum Dis 2014, 73: $2160-2167$.

[2] Ueda N, et al. Clinical and Genetic Features of Patients With TNFRSF1A Variants in Japan: Findings of a Nationwide Survey. Arthritis Rheumatol 2016, 68: 2760-2771.

Disclosure of Interests: None declared

DOI: 10.1136/annrheumdis-2019-eular.5204
Diagnostics and imaging procedures

\section{THU0594 \\ CLINICAL VERSUS IMAGING REMISSION IN JUVENILE IDIOPATHIC ARTHRITIS (JIA): PRELIMINARY RESULTS OF THE REMECO STUDY}

Marta Mazzoni ${ }^{1,2}$, Silvia Merlo ${ }^{1}$, Angela Pistorio ${ }^{3}$, Stefania Viola $^{2}$,

Alessandro Consolaro ${ }^{1,2}$, Angelo Ravelli ${ }^{1,2}$, Clara Malattia ${ }^{1,2} .{ }^{1}$ Università degli studi di Genova, Genova, Italy, ${ }^{2}$ IRCCS Istituto Giannina Gaslini, Clinica Pediatrica e Reumatologia, Genova, Italy; ${ }^{3}$ IRCCS Istituto Giannina Gaslini, Epidemiologia e Biostatistica, Genova, Italy

Background: remission is becoming a realistic target in JIA, but clinical remission (CR) may not accurately reflect real absence of synovitis. It would be desirable to have instruments to predict the risk of relapse in patients in $\mathrm{CR}$ in order to establish the most appropriate therapeutic strategy. Despite in RA the role of imaging to predict disease flare is established, this field has remained almost unexplored in JIA.

Objectives: 1) to investigate the prevalence of musculoskeletal ultrasound (MSUS)-detected subclinical synovitis in JIA patients in CR; 2) to establish which and how many joints should be scanned to reliably assess remission; 3) to evaluate the persistence of subclinical synovitis over the time; 4) to investigate whether subclinical synovitis entails a risk of disease flare; 5) MSUS data will be integrated with serum levels of inflammatory biomarkers to develop a multidimensional measure of remission. Methods: it is a longitudinal prospective 4 years study started on November 2017. So far we have enrolled 99 consecutive JIA patients who met the Wallace criteria for CR. For each patient 46 joints were scanned for synovial hyperplasia/joint effusion and PD signal, all graded semiquantitatively on a $0-3$ scale independently by 2 expert ultrasonographers. Subclinical synovitis was defined when total synovitis score for each joint was $\geq 2$. MSUS was performed at baseline and at 6 month follow up visit. At inclusion serum assays have been stored to determine levels of inflammatory biomarkers (S100A8/9-A12, bFGF, IL-6, IL-10, CXCL9-10, VEGF, YKL40). A flare of synovitis was defined as a recurrence of clinically active arthritis.

Results: 99 patients $(79.8 \% \mathrm{~F}$; median age $11.3 \mathrm{y}$; median disease duration $5.3 \mathrm{y}$; median $\mathrm{CR}$ duration $1.6 \mathrm{y}$ ) were included. Thirty-eight/99 (38.4\%) patients had persistent oligoarthiritis; $34 / 99$ (34.3\%) extended oligoarthiritis; 22/99 (22.2\%) polyarthiritis; $5 / 99$ (5.1\%) systemic arthritis. Fifty-nine/99 (59.6\%) patients were in CR on medication. Subclinical synovitis was detected in 54/99 (54.5\%; 95\% Cl: 45.2 - 65.5\%) patients, PD in $18 / 99(18.2 \%$; $95 \% \mathrm{Cl}: 11.1-27.2 \%)$ patients; subclinical tenosynovitis in $7 / 99$ (7.1\%; 95\% Cl: 2.9 - 14\%) patients. Subclinical synovitis was found more frequently in the ankle [31/54 (57.4\%) patients] and wrist joints $[17 / 54(31.5 \%)$ patients]. No patients had subclinical synovitis in the hip. A 14-joint reduced count including bilateral knee, ankle (tibiotalar, subtalar and talonavicular joints), wrist (radiocarpal and intercarpal joints) and elbow joints, detected $92.6 \%$ of children with subclinical synovitis. Twenty-five/99 (25.2\%) patients in persistent CR were reassessed with MSUS at a follow up visit (median follow up duration 7 months): $82.3 \%$ of patients showed persistent subclinical synovitis. Sixty-four/99 $(64.6 \%)$ patients had a clinically follow up of at least 6 months and 9/64 (14\%) patients experienced a disease flare (median time to flare 6.6 months) Six/9 $(66.7 \%)$ patients who experienced a relapse had subclinical synovitis at baseline.

Conclusion: our preliminary results confirm the discrepancy between clinical and imaging remission and that clinical evaluation may not sensitive to detect an inflammation-free state. Bilateral US assessment of the elbow, wrist, knee and ankle joints is reliable to detect subclinical synovitis. So far, patients who have relapsed are a small percentage, but to extend follow up is crucial to test predictive value of MSUS. Imaging findings will be combined with serum biomarkers leading to the construction of a predictive model.

\section{REFERENCES:}

[1] De Lucia O, et al. Baseline ultrasound examination as possible predictor of relapse in patients affected by juvenile idiopathic arthritis (JIA). Ann Rheum Dis. 2018 Oct;77(10):1426-1431.

Disclosure of Interests: Marta Mazzoni: None declared, Silvia Merlo: None declared, Angela Pistorio: None declared, Stefania Viola: None 
declared, Alessandro Consolaro Grant/research support from: AbbVie, Pfizer, Angelo Ravelli Grant/research support from: Angelini, AbbVie, Bristol-Myers Squibb, Johnson \& Johnson, Novartis, Pfizer, Reckitt Benkiser, and Roche, Consultant for: Angelini, AbbVie, Bristol-Myers Squibb, Johnson \& Johnson, Novartis, Pfizer, Reckitt Benkiser, and Roche, Speakers bureau: Angelini, AbbVie, Bristol-Myers Squibb, Johnson \& Johnson, Novartis, Pfizer, Reckitt Benkiser, and Roche, Clara Malattia: None declared

DOI: 10.1136/annrheumdis-2019-eular.7082

\section{THU0595 DEVELOPMENT OF AN AUTOMATED SEGMENTATION ALGORITHM TO IDENTIFY BONES OF THE HAND}

Adwaye Rambojun ${ }^{1}$, William Tillett ${ }^{2,3}$, Neill Campbell ${ }^{4}$, Tony Shardlow ${ }^{1}$. ${ }^{1}$ University of Bath, Mathematical Sciences, Bath, United Kingdom; ${ }^{2}$ University of Bath, Pharmacology, Bath, United Kingdom; ${ }^{3}$ Royal National Hospital For Rheumatic Diseases, Bath, United Kingdom; ${ }^{4}$ University of Bath, Computer Science, Bath, United Kingdom

Background: The evaluation of structural damage with plain radiography is important to clinicians and patients. Standard scoring methods include the Sharp-van der Heijde (SVdH) and Ratingen methods [1] however these systems are time-consuming. Therefore, it is difficult to perform large cohort studies. We set out to develop an automated algorithm to identify bones on plain radiographs as a step towards developing automated quantification of structural damage for use on large datasets.

Objectives: To develop a novel algorithm to segment outlines of finger bones in hand radiographs.

Methods: 101 hand radiographs were gathered from the Bath longitudinal cohort (UK). All patients fulfilled the CASPAR criteria for Psoriatic Arthiritis (PSA). None of the patients had damage on SVdH and Ratingen scoring (blinded). The metacarpal (MC), proximal phalanx (PP), middle phalanx (MP), and distal phalanx (DP) in the right index finger were delineated by a rheumatologist. These outlines were used to build a statistical model of the shape using a Gaussian Process Latent Variable Model (GPLVM) [2]. Bones are segmented by matching the shape on a radiograph to the statistical model.

Results: The performance of the matching algorithm was compared with a traditional algorithm (snakes) using the Adjusted Rand Score (ARND). The ARND score measures the similarity of the segmentation with the ground truth. A perfect segmentation has a score close to 1 . We tested the algorithm on $9 \mathrm{PP}, 9 \mathrm{MP}$ and $8 \mathrm{DP}$ and $6 \mathrm{MC}$ bones in the right index finger. The results are reported in table 1 . We report a mean improvement in ARAND of $0.19,0.87,0.43$ and 0.30 for the PP, MP, DP and MC respectively.

Conclusion: We report a reliable algorithm for the identification of metacarpal, proximal, middle and distal phalanx bones of the hand. Future work will focus on using the output of the segmentation algorithm to track damage progression over time.

\section{REFERENCES:}

[1] Van der Heijde, D., PAULUS, H., and SHEKELLE, P. (2000). How to read radiographs according to the Sharp/vander Heijde method. Discussion: Heterogeneity in rheumatoid arthritis radiographic trials. Issues to consider in a metaanalysis. Journal of rheumatology, 27(1):261-263.

[2] Titsias, M. K. and Lawrence, N. D. (2010). Bayesian Gaussian process latent variable model. In International Conference on Artificial Intelligence and Statistics, pages $844-851$

Table 1. Adjusted RAND scores for comparing our algorithm to a traditional one (snakes)

\begin{tabular}{lccc}
\hline & Bone & $\begin{array}{c}\text { Snakes } \\
\text { ARAND }\end{array}$ & $\begin{array}{c}\text { Shape matching } \\
\text { ARAND }\end{array}$ \\
\hline Case 1 & PP & 0.70 & 0.95 \\
Case 2 & PP & 0.89 & 0.96 \\
Case 3 & PP & 0.82 & 0.96 \\
Case 4 & PP & 0.72 & 0.94 \\
Case 5 & PP & 0.53 & 0.96 \\
Case 6 & PP & 0.87 & 0.97 \\
Case 7 & PP & 0.79 & 0.96 \\
Case 8 & PP & 0.74 & 0.96 \\
Case 9 & PP & 0.88 & 0.97 \\
Case 1 & MP & 0.79 & 0.95 \\
Case 2 & MP & 0.75 & 0.95 \\
Case 3 & MP & 0.75 & 0.94
\end{tabular}

$\begin{array}{llll}\text { Case } 4 & \text { MP } & 0.72 & 0.95 \\ \text { Case 5 } & \text { MP } & 0.77 & 0.96 \\ \text { Case 6 } & \text { MP } & 0.51 & 0.96 \\ \text { Case 7 } & \text { MP } & 0.76 & 0.96 \\ \text { Case 8 } & \text { MP } & 0.77 & 0.96 \\ \text { Case 9 } & \text { MP } & 0.83 & 0.97 \\ \text { Case } & \text { MP } & 0.77 & 0.93\end{array}$

10

Key: Adjusted Rand Score (ARND) score measures the similarity of the segmentation with the ground truth. A perfect segmentation has a score close to 1. Metacarpal (MC), proximal phalanx (PP), middle phalanx (MP), and distal phalanx (DP)

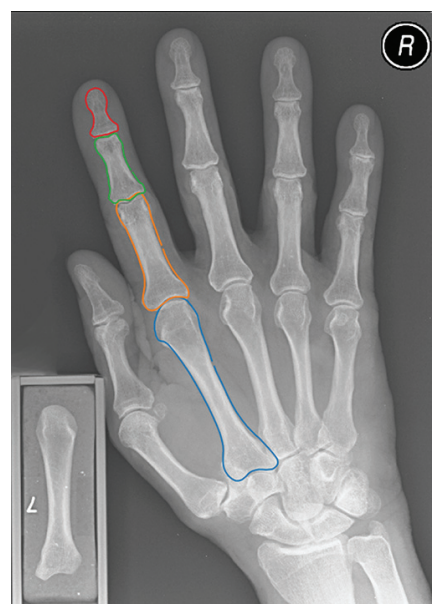

Figure 1. Shape matching algorithm output demonstrating segmented outlines of the DP, MP, PP and MC in red, green, orange, and blue respectively.

Disclosure of Interests: Adwaye Rambojun: None declared, William Tillett Grant/research support from: AbbVie, Celgene, and Lilly, Consultant for: AbbVie, Celgene, Lilly, Novartis, and Pfizer, Speakers bureau: Abbvie Celgene, Lilly, Janssen, Novartis, UCB, and Pfizer, Neill Campbell: None declared, Tony Shardlow: None declared

DOI: 10.1136/annrheumdis-2019-eular.2336

\section{THU0596 DIAGNOSTIC VALUE OF ULTRASOUND AND DUAL ENERGY COMPUTED TOMOGRAPHYTO ACHIEVE ACR- EULAR GOUT CLASSIFICATION CRITERIA IN REAL LIFE CLINICAL PRACTICE}

André Ramon ${ }^{1}$, Marie Schmitt ${ }^{1}$, Romaric $\mathrm{Ne}^{2}$, Pierre Emmanuel Berthod ${ }^{2}$, Hervé Devilliers ${ }^{3}$, Jean Francis Maillefert ${ }^{1}$, Paul Ornetti ${ }^{1} .{ }^{1}$ Dijon University Hospital, Rheumatology, Dijon, France; ${ }^{2}$ Dijon University Hospital, Radiology, Dijon, France; ${ }^{3}$ Dijon University Hospital, Internal Medicine, dijon, France

Background: 2015 ACR/EULAR gout classification criteria (1) include ultrasound with double contour (DC) sign as key ultrasound features and dual energy computed tomography (DECT) with evidence of urate deposition. The positivity of either DECT or ultrasound allows 4 points in addition to others clinical and biological criteria to classify as gout is $\geq 8 / 23$. However, in routine care, the imaging modality that should be promoted remains unclear between ultrasound or DECT.

Objectives: To validate a possible diagnostic algorithm for the clinical use of DECT and ultrasound in suspected gouty arthritis.

Methods: We conducted a single-center prospective study in the Rheumatology Department of Dijon University Hospital from july 2016 to december 2018, including all patients hospitalized for suspected gouty arthritis Each patient received joint aspiration if possible, an ultrasound assessment (DC sign and/or tophus) and DECT scanning of symptomatic joints All these examinations were performed blind of the clinical data and results of joint aspiration. The gold standard used for this study was the 2015 ACR/EULAR gout classification criteria. We have established two 